\title{
An Experimental Device for Measuring Cutting Forces of a Cutting Tool
}

\author{
Kui Chen ${ }^{1, a}$, Zongxi Cai ${ }^{2, b}$, Zhende $H_{o u}^{2, c}$ and Chuanyong Qu ${ }^{2, d, *}$ \\ ${ }^{1}$ State Key Laboratory of Shield Machine and Boring Technology, Zhengzhou, China \\ ${ }^{2}$ School of Mechanical Engineering, Tianjin University, Tianjin, China \\ a 13721674346@163.com, ${ }^{\mathrm{b}}$ zxcai@tju.edu.cn, c hou@tju.edu.cn, ${ }^{\mathrm{d}}$ qu_chuanyong@tju.edu.cn \\ *corresponding author
}

Keywords: soil, cutting, cutting resistance, measurement sensor, cutting force.

\begin{abstract}
In this paper, a soil cutting test rig was developed equipping with two force sensors and a displacement sensor. The equipment could perform measurements continuously at various cutting speeds when the cutting tools worked in the soils. The cutting tool is a rectangle blade. It can moves horizontally and cuts a soil sample at a selected angle. The forces and the displacement of the cutting tools can then be obtained by the sensors and recorded for future engineering use. Verification test was then conducted to determine the performance of the developed rig. Marine sediment soil was tested. The cutting resist force, vertical force and the relationship with respect to cutting distance can be measured and the new device can be used in the cutting machines in the future.
\end{abstract}

\section{Introduction}

Soil cutting efficiency of a cutting tool depends on its shape, size, cutting speed, cutting depth and the soil mechanical properties in civil, dredging, agriculture, tunnel, engineering, etc[1,2,3]. Many studies have been focused on how to design a productive tool. Theoretical analysis and experimental techniques have been employed to achieve adequate understanding about the efficient of soil-cutting tools in various ground works. The mechanical properties of soils are quite complex, many factors are associate with the strength and deformation properties, such as moisture content, soil particle sizes distribution and composition. Although theoretical soil mechanical models and numerical calculation methods have been employed to describe and estimate the interactions between soils and cutting tools [4,5], it is still necessary to determine these interactions by experiments [6,7]. It was observed experimentally that the force acted on the cutting tool during cutting soil is proportional to the square of the speed [6]. Literature [7] studied the soil cutting process of the earth auger, which the cutting process was analyzed by the experiments in terms of the vertical force and the torque. It found that the torque was the almost same when the rotation speed differs though it became larger when the pushing force increases.

The objective of this study is to develop a soil cutting test rig equipped with two force sensors and a displacement sensor that could perform measurements continuously at various cutting speeds. The cutting tool is a rectangle blade which can move horizontally and cut soil in a selected angle. Verification test was conducted to determine the performance of the developed rig.

\section{Material and method}

The test rig developed comprises a driver system, one displacement sensor, two forces sensors, one force moment sensor and a cutting tool. The main aim is to measure the cutting resistance forces with respective to cutting distance. Fig. 1 illustrates the developed apparatus schematically.

The function of the driver system is to actuate the cutting tool or the stage to move horizontally. When the speed adjusting motor drives the lead screw to turn, the cutting tool moves along the screw and cut soil. Between the cutting tool and the stage, two sensors are installed. One is a force sensor for measuring the vertical force noted force $\mathrm{Y}$ acted on the cutting tool. The other is a 
complex sensor for measuring both the cutting resistance (horizontal force) noted force $\mathrm{X}$ and the bending moment caused by force $\mathrm{X}$ and force $\mathrm{Y}$ at the position occupied by the force moment sensor. Another transducer used is a wire displacement sensor to measure the moving distance of cutting. It was installed on the left support of bearing and its wire's free end was fixed to the stage, the moving distance of which is equal to the cutting distance of the cutting tool.

The stage, complex sensor and Force Y sensor were assembled in the configuration shown in Figure 1 . The cutting tool is a square blade with dimension $200 \mathrm{~mm} \times 200 \mathrm{~mm}$. It is installed to the right end of the sensor force $X$ by two axis pins, which make the cutting tool can rotate 30,45 and 60 degree with respect to $\mathrm{X}$ axis respectively.

The cutting speed ranges from $0.3 \mathrm{~m}$ to $10 \mathrm{~m} / \mathrm{min}$; the maximum force can be produced by the rig is $8000 \mathrm{~N}$; the maximum cutting distance is $1.5 \mathrm{~m}$. A computer was used to record all the measured data.

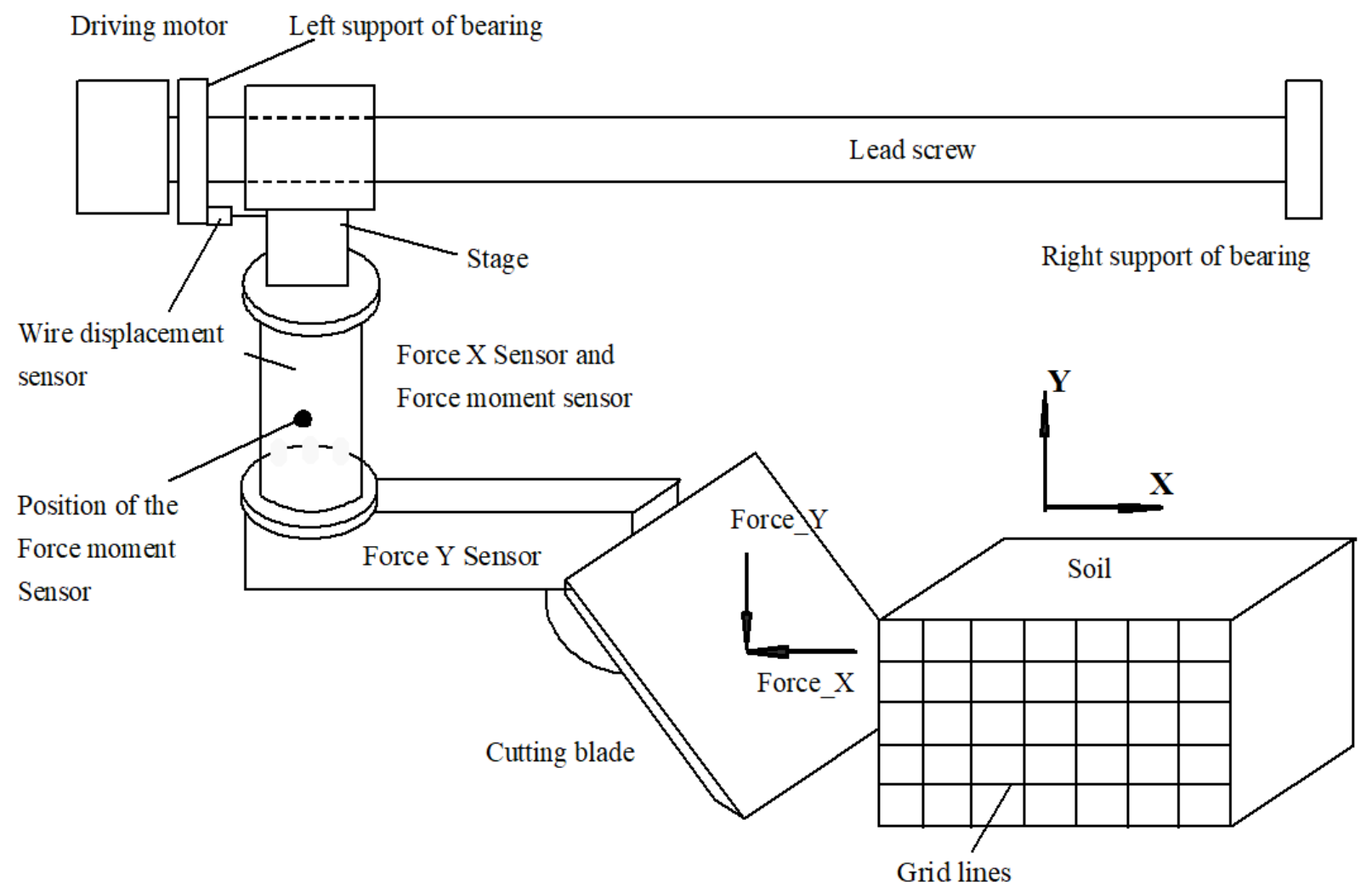

Figure 1 Schematic of the apparatus developed for the cutting test.

\section{Experimental procedure}

A basic test was conducted to analyse the performance of the apparatus. The tested soil was sediment soil from marine with moisture content of $20 \%$. The soil was compacted in 25 mm layers with width of $200 \mathrm{~mm}$ and length of $1500 \mathrm{~mm}$, along which the cutting tool moving. Grid lines were printed on the two lateral sides of the soil to conveniently observe the deformation pattern when it is cut.

The moving speed of the cutting tool is $1.33 \mathrm{~m} / \mathrm{min}$ and it cut into the soil at an angle of 30 degree with respect the cutting direction. When the cutting tool edge was touching the soil, the computer began to record the measured data of the force $\mathrm{X}$, force $\mathrm{Y}$, force moment and displacement with acquisition interval 30ms. Figure 2 shows the deformation pattern of the soil when the cutting blade cut into it. 


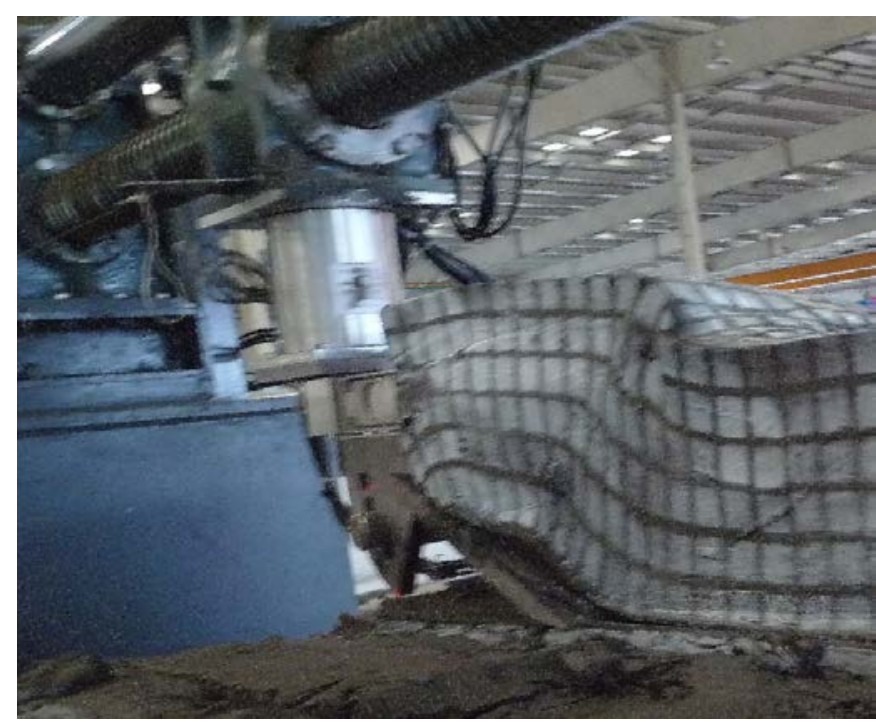

Figure 2 Deformed grid lines on the soil lateral surface.

\section{Results}

The measured forces versus the measured displacement are plotted in Figure 3. The curves of blue and red represent the force $\mathrm{X}$ and force $\mathrm{Y}$ respectively in Figure 3(a). The two curves have similar shapes. The force $\mathrm{X}$ and force $\mathrm{Y}$ increase with displacement until they reach an asymptotic level, after that their values remained more or less constant with displacement, though there are some fluctuations in the curves. The asymptotic constant value of force $\mathrm{X}$ is about $740 \mathrm{~N}$ and that of force Y $250 \mathrm{~N}$, which the former is much larger than that of the later.

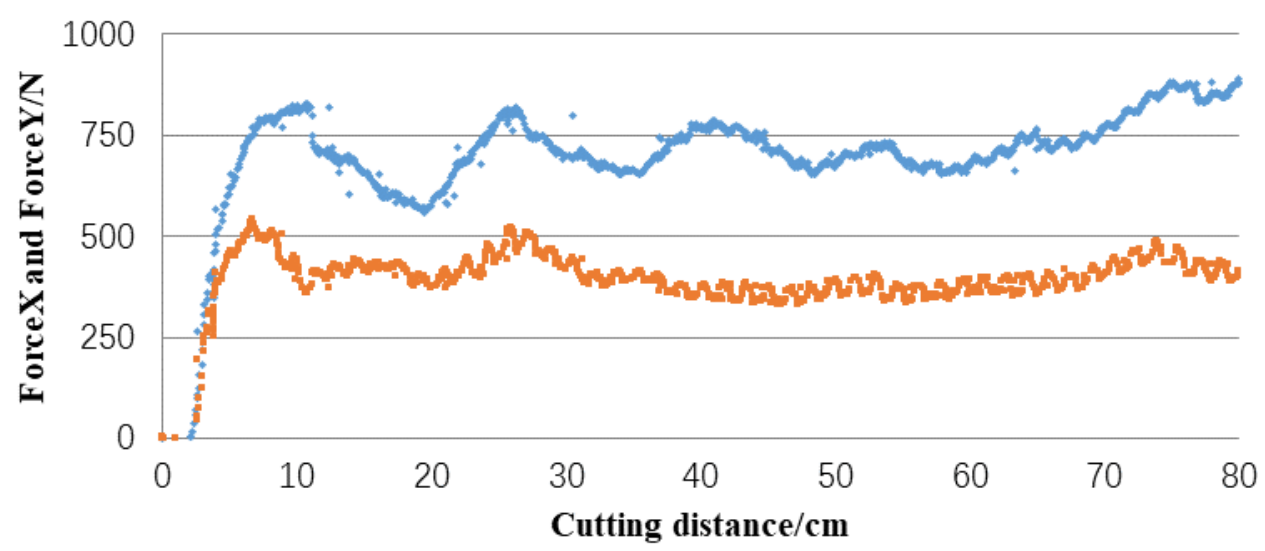

(a)

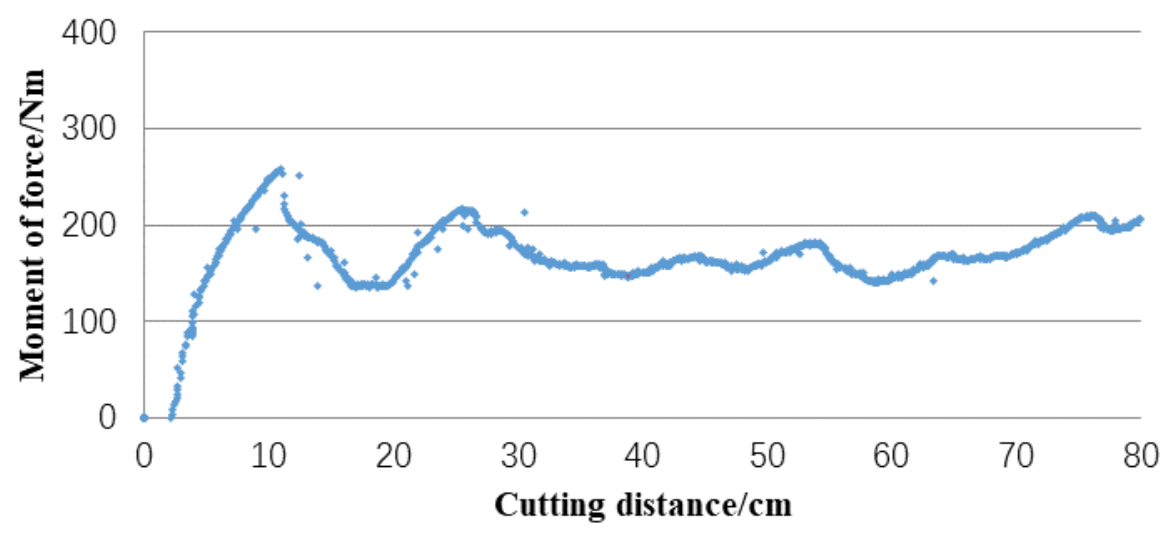

(b)

Figure 3 Diagrams of measured data versus the cutting displacement 
It is predictable that if the angle of the blade increases to 45 or 60 degree the vertical force $\mathrm{Y}$ will decrease further, which implies that the cutting resistance force or force $\mathrm{X}$ plays a relative important role in the cutting. The reason is obvious: during soil cutting test, the vertical action of the soil on the blade is mainly the weight of the cut soil.

Figure 3(b) presents the curve of bending moment versus the cutting displacement. The point of resultant of force $\mathrm{X}$ and force $\mathrm{Y}$ can be calculated from the bending moment and the horizontal and vertical distance between the point and the force moment sensor. The pattern of the curve is similar to those in Figure 3(a). After cutting about 8cm, the curves of force X, force Y in Figure 3(a) and the force moment in Figure 3(b) all become nearly constant, which means that the point position of resultant of force $\mathrm{X}$ and force $\mathrm{Y}$ does not change much.

\section{Conclusions}

A soil cutting test apparatus has been developed and which can measure the cutting resistance forces and the relationships of the forces with respect to the cutting distance. The main features of the test rig are as follows: The cutting speed ranges from $0.3 \mathrm{~m}$ to $10 \mathrm{~m} / \mathrm{min}$; the maximum force can be produced by the rig is $8000 \mathrm{~N}$; the maximum cutting distance is $1500 \mathrm{~mm}$; the cutting blade, with dimension $200 \mathrm{mmm} \times 200 \mathrm{~mm}$, can cut soil at an angle of 30, 45 and 60 degrees respectively. An experimental verification was performed, and the experimental results confirmed the availability of the apparatus.

\section{Acknowledgements}

This work was supported by the National Basic Research Program of China (973 Program, Grant no. 2013CB035042) and the National Natural Science Foundation of China (NSFC, Grant No. 11372213, 11172200).

\section{References}

[1] Moghaddam, R. Y., Kotchon, A., \& Lipsett, M. G. (2012). Method and apparatus for on-line estimation of soil parameters during excavation.Journal of Terramechanics, 49(49), 173-181.

[2] Mouazen, A. M., Neményi, M., Schwanghart, H., \& Rempfer, M. (1999). Tillage tool design by the finite element method: part 2. experimental validation of the finite element results with soil bin test.Journal of Agricultural Engineering Research,72(1), 53-58.

[3] Agüera, J., Carballido, J., Gil, J., Gliever, C. J., \& Perez-Ruiz, M. (2013). Design of a soil cutting resistance sensor for application in site-specific tillage.Sensors,13(5), 5945-57.

[4] Mo, L., Yang, Y., Li, G., Chen, D., Sun, H., \& Jin, T. (2015). Design and analysis of bionic cutting blades using finite element method.Applied Bionics \& Biomechanics,2015(2), 1-7.

[5] Onwualu, A. P., \& Watts, K. C. (1998). Draught and vertical forces obtained from dynamic soil cutting by plane tillage tools.Soil \& Tillage Research,48(4), 239-253.

[6] Aluko, O. B., \& Seig, D. A. (2000). An experimental investigation of the characteristics of and conditions for brittle fracture in two-dimensional soil cutting.Soil \& Tillage Research,57(3), 143157.

[7] Malaguti, F. (2005). Cutting and impedance model of soil-excavator interaction. Isarc Proceedings. 